\title{
Valores Éticos que Norteiam As Ações dos Trabalhadores da Saúde de uma Unidade de Terapia Intensiva
}

\author{
Silveira, Rosemary Silva da; Martins, Cleusa Rios; Lunardi, Valéria Lerch; Ávila, Liziani \\ Iturriet; Gonçalves, Naiane Glaciele da C.; Saioron, Isabela \\ Universidade Federal do Rio Grande — anacarol@mikrus.com.br
}

Introdução: a convicção de que falta ética ou de que é necessário resgatar valores éticos em nossas práticas, pode revelar uma insatisfação com o comportamento estabelecido pelos trabalhadores da saúde. Apesar de cada ser possuir sua construção de subjetividade, seus valores, crenças e ideais, os trabalhadores de saúde podem comprometer sua construção de sujeito autônomo e ético no ambiente de trabalho ao deparar-se com situações desfavoráveis, conflituosas, de desrespeito, de desvalorização, de não interação entre profissionais e usuários. Tais vivências podem influenciar o comportamento dos trabalhadores da saúde e, sobremaneira, interferir no processo de (des)construção para o exercício da autonomia e da ética. Objetivo: analisar os valores éticos que norteiam as ações dos trabalhadores da saúde de uma Unidade de Terapia Intensiva (UTI). Metodologia: Realizou-se uma pesquisa qualitativa, com 40 trabalhadores da saúde de uma UTI de um Hospital do sul do país. Inspirada na Etnoenfermagem de Leininger, desenvolveram-se quatro fases de observação; uma fase de entrevista e quatro fases de análise. Resultados e Discussões: Os trabalhadores destacaram a necessidade de pautar seu fazer em valores como a confiança, a harmonia, a amizade, o diálogo e o respeito, possibilitando a busca de objetivos comuns, com possíveis repercussões para a efetivação do cuidado. o diálogo foi compreendido como uma dimensão ética do fazer, pois possibilita relações interpessoais favoráveis, construindo-se nas diferenças, podendo assim, influenciar o processo de legitimação de valores. o processo de cuidar envolve vontades, interesses, valores, oportunidades de fazê-lo acontecer consciente ou inconscientemente, pois do mesmo modo que os trabalhadores valorizam e compromete-se com o cuidado ao usuário, em outros momentos, parecem realizá-lo de maneira mecânica, necessitando do controle de quem possui autoridade. Conclusão: Considera-se que, o trabalhador precisa se reconhecer como um sujeito ético direcionando suas ações e a continuidade do cuidado a partir de valores como compaixão, confiança, compromisso, respeito, honestidade. para tanto, é preciso existir a possibilidade de o trabalhador envolver-se, sensibilizar-se, comprometer-se, participar das decisões, o que requer respeito, estímulo e abertura de espaços no contexto de trabalho. a interiorização de valores morais nas ações dos trabalhadores da saúde possibilita o desenvolvimento de relações saudáveis entre si, o que é fundamental num contexto como o da UTI, que necessita da aproximação dos trabalhadores, do envolvimento, do diálogo, da tomada de decisões conjuntas, do respeito às diversidades, da busca de consenso, de modo a proporcionar um cuidado mais seguro e significativo.

\footnotetext{
Silveira, Rosemary Silva da; Martins, Cleusa Rios; Lunardi, Valéria Lerch; Ávila, Liziani Iturriet; Gonçalves, Naiane Glaciele da C.; Saioron, Isabela. Valores Éticos que Norteiam As Ações dos Trabalhadores da Saúde de uma Unidade de Terapia Intensiva. In: Anais do Congresso Internacional de Humanidades \& Humanização em Saúde [= Blucher Medical Proceedings, num.2, vol.1]. São Paulo: Editora Blucher, 2014. ISSN 2357-7282 DOI 10.5151/medpro-cihhs-10680
} 